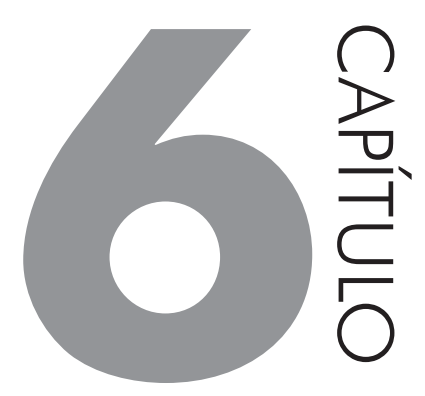

\title{
PREDICAR COM CONSTRUÇÃO COM VERBO SUPORTE
}

MARCIA DOS SANTOS MACHADO VIEIRA ${ }^{1}$

\section{INTRODUÇÃO}

Trata-se, neste texto, da construção com verbo suporte como um padrão gramatical do conhecimento linguístico que gera predicadores complexos, os quais exibem diversas configurações no Português e se prestam à explicitação de estados de coisas (dinâmicos ou não). Descrevem-se (i) os atributos de forma e função minimamente pareados nessa construção, (ii) potenciais relações entre predicadores complexos oriundos dessa construção, bem como destes e de predi-

1 A partir da escolha do tema, faço minha homenagem e meu agradecimento à querida Professora Silvia Brandão. Uma amostra de sua generosidade vem do dom de se entregar ao escrutínio de um assunto: ler até obras francesas sobre verbos suportes em reuniões de orientação. Sua forte presença no meu ofício está, entre vários aspectos, no prazer em fazer pesquisa, na preocupação com o significado social dos usos da Língua Portuguesa, fundamental no Projeto PREDICAR - Formação e expressão de predicados complexos (consequência natural das proveitosas conversas sobre predicações e verbos gramaticalizados), e na história de investigações sobre a temática fomentadas nesse projeto. 
cadores simples, e (iii) algumas possibilidades de significado funcional (semântico, discursivo, pragmático e social) de seus usos.

Tal descrição, que se iniciou, por ocasião da pesquisa de Doutoramento (MACHADO VIEIRA, 2001), sob um olhar teórico-metodológico para o qual foi marcante a contribuição da Gramática Funcional de DIK (1997) bem como de outras orientações do Funcionalismo, desenha-se, aqui, sob uma nova perspectiva funcionalista, mais precisamente a funcional-construcionista (com forte influência de TRAUGOTT; TROUSDALE, 2013; GOLDBERG, 1995 e 2006; e HILPERT, 2014).

Construção, no âmbito da Linguística Funcional-Cognitiva que se volta para a Gramática das Construções, é uma unidade basilar da língua (GOLDBERG, 1995, 2006): uma combinação de forma (prosódica, fonético-fonológica, morfológica e sintática) e função/significado (semântica(o), discursiva(o), pragmática(o) e social).

Para Traugott; Trousdale (2013), o mapeamento dos padrões construcionais da gramática de uma língua implica a concepção teórico-metodológica de quatro níveis de esquematicidade (desde um nível mais geral, com mais slots para preenchimento e abstrato - possivelmente um primitivo universal - até um nível mais específico, preenchido e concreto): 1) macroconstruções/esquemas construcionais (pareamentos com possibilidades diversas de preenchimento); 2) mesoconstruções/ subesquemas construcionais (pareamentos com similaridades observáveis horizontalmente e sob relação de herança com as macroconstruções); 3) microconstruções (pareamentos individuais licenciados por mesoconstruções que, embora ainda abstratos, têm potencial de se instanciarem/concretizarem em texto/discurso) e 4) construtos (os usos efetivos das microconstruções em textos). Os construtos é que, por inovação e depois convencionalização, podem promover mudança construcional (quando a alteração ou ocorre no polo da forma ou no polo da função de um padrão construcional/pareamento forma-função já existente na rede) ou construcionalização (processo que implica nova forma-nova função pareadas e, por conseguinte, um novo padrão construcional, um novo nó na rede de padrões gramaticais). O processo de construcionalização pode ser gramatical ou lexical, resultando, respectivamente, numa construção com valor (mais ou menos) procedural na língua (com potencial de licenciar outros padrões construcionais menos esquemáticos e construtos) ou num padrão construcional com valor não procedural e com pareamento forma-conteúdo cristalizado/lexicalizado no mundo biossocial ${ }^{2}$.

2 Exemplos de instâncias do segundo tipo construcional, que, no âmbito da predicação aqui em foco, remetem a entidade ou estado de coisas do mundo biossocial são:

(i) “Web 'quebra galho' de namorados esquecidos

Internet tem diversas alternativas que podem causar boa impressão. Confira sugestões on-line para criar cartões personalizados ou ver estrelas a dois.” (http://g1.globo.com/Noticias/ 
Além do parâmetro de esquematicidade do padrão construcional, influirão também, nesse mapeamento, os parâmetros de produtividade (de ocorrência/frequência de construto e de tipo/frequência e regularidade de padrão construcional), composicionalidade (grau de transparência e opacidade semântica da relação dos componentes lexicais envolvidos num padrão construcional e seu grau de analisabilidade morfossintática) e contextualidade (condições discursivas, pragmáticas, sociais e cognitivas de conceptualização de um estado de coisas).

\section{CONSTRUÇÃO DE PREDICAÇÃO COM VERBO SUPORTE}

Para predicar um estado de coisas (ação, processo, posição ou estado, possibilidades de acionalidade segundo DIK, 1997:115), pode-se recorrer a um destes tipos de predicadores verbais: predicadores simples ou predicadores complexos. Os predicadores complexos envolvem, entre outras possibilidades de verbos gramaticalizados, os verbos suportes (também conhecidos, na literatura, como verbalizadores $^{3}$ ou verbos leves, como em RAPOSO, 2013). Por exemplo:

"A cereja no bolo é a demonização que é feita no seguinte parágrafo: "Quando se fala em livre conhecimento, entre outras coisas se quer dizer que se é contra criminalizar alguém por baixar música da internet ou por fazer uma cópia de um livro na faculdade.” (...) É óbvio que ninguém vai sair por aí prendendo quem baixou MP3 da web ou copiou um livro no xerox da faculdade. Esses são sintomas de uma sociedade subdesenvolvida como a nossa." (https://jornalggn.com.br/blog/luisnassif/a-questao-dos-direitos-autorais, acesso em 05/01/2018).

Verbo suporte é o nome dado a usos de formas verbais que operam rotineiramente sobre um elemento não-verbal (em geral, um constituinte nominal substantivo ou adjetivo -, embora seja possível outra configuração ${ }^{4}$ ) desprovido de sua função primária referencial ou atributiva, conferindo-lhe estatuto verbal e formando com ele uma unidade funcional predicante, ou seja, um predicador complexo. Por exemplo:

Tecnologia/0, MUL50854-6174,00-WEB+QUEBRA+GALHO+DE+NAMORADOS+ESQUE CIDOS.html, acesso em 05/01/2018)

(ii) "Acho que é ponta-direita”, arrisca Minelli. "Gosto dele na ponta-esquerda, fazendo o papel que Mário Sérgio fazia”, diz Renato. E o próprio Valdo, que já quebrou galho como centroavante, sonha em se ver numa das meias num futuro próximo.” (Placar Magazine, nov. 1985)

Exemplos de instâncias do primeiro tipo construcional seriam: fazer (uma) homenagem; fazer (um) agradecimento e outros na próxima seção do capítulo.

3 "Operadum auxiliar de verbalização de elementos não-verbais" (cf. MACHADO VIEIRA, 2001).

4 Por exemplo: levar/ter em consideração, dar de ombros. 
"Eletrobras faz negociação de dívidas atrasadas com consumidores no Acre." (https://g1.globo.com/ac/acre/noticia/eletrobras-promove-negociacao-de-dividas-atrasadas-com-consumidores-no-acre.ghtml, acesso em 05/01/2018).

"Assim como o Super FC também confirmou, o Grêmio deu o aval e o Cruzeiro já negocia salários com o atacante Marcelo Moreno, que não será aproveitado pelo Tricolor Gaúcho em 2014.” (http://www.otempo.com.br/ superfc/cruzeiro-d\%C3\%A1-chap\%C3\%A9u-no-flamengo-e-contrata-volante-rodrigo-souza-1.764196, acesso em 05/01/2018).

"TV Brasil faz questão de ser cada dia mais insignificante." (...) "Aliás, é bem o caso de desconfiar se a TV Brasil, com as atitudes que são tomadas, não é propositadamente dirigida para não dar certo." (https://www.correiodobrasil.com.br/tv-brasil-faz-questao-de-ser-cada-dia-mais-insignificante/, acesso em 05/01/2018)

"Inovação deve levar em conta singularidades." (http://jcrs.uol.com.br/site/ noticia.php?codn=77372, acesso em 05/01/2018)

O predicador complexo passa a indicar a estrutura de participantes da predicação verbal. O verbo suporte partilha com o elemento não-verbal (sintagma nominal, sintagma adjetival, sintagma preposicional) a função de determinar o número e a natureza dos papéis participantes ${ }^{5}$, que, por sua vez, se compatibilizarão, no uso, com os papéis argumentais de uma construção gramatical oracional de predicação verbal (pessoal ou impessoal; transitiva ou intransitiva). Isso pode ser percebido mediante os diferentes papéis dos termos que preenchem a posição de sujeito dessas perífrases: em construções com verbo-suporte fazer, por exemplo, detectam-se termos com as funções de agente (As crianças fizeram bagunça.), força (O temporal fez um estrago nos telhados das casas.), paciente (A criança fez uma cirurgia), tema (O rapaz faz parte da equipe.). E, inclusive, pode ser notado pelo fato de haver expressões com verbo suporte impessoais: fazer sol, fazer chuva, dar uma trovoada, dar uma chovida. Exemplos, ainda, com o verbo suporte dar, além do acima com a expressão dar o aval, que ajudam a confirmar isso são:

"Deu ruim e pode piorar! Enfermeira faz procedimento para aumentar os lábios e fica com bico de pato.” (...) “Não precisa nem dizer, tá na cara que deu errado. Foi assim que a enfermeira turca Merve Keles ficou logo após um preenchimento labial malsucedido." (https://hora7.r7.com/fotos/deu-ruim-e-pode-piorar-enfermeira-faz-procedimento-para-aumentar-os-labios-e-fica-com-bico-de-pato-10072017\#!/foto/1, acesso em 05/01/2018)

5 Os papéis participantes constituem partes focais da cena representada pela semântica dos predicadores verbais. 
"O fantasmaço Granollers jogou muito tênis e bateu o favorito Wawrinka. Thomaz Bellucci poderia dar uma olhadinha nos jogos desse espanhol para entender como se pode fazer muito com pouco. Deu gosto ver a vitória do rapaz, especialmente na hora da onça beber água no $3^{\circ}$ set.” (http://paulocleto.ig.com.br/index.php/tag/verdasco/, acesso em 0/01/2018)

O deslocamento do núcleo irradiador da estrutura de participantes da predicação do verbo para o complexo verbo e elemento não-verbal dá-se em virtude da natureza (semi)gramaticalizada de certos usos de formas verbais nessas condições, da integração semântica e sintática de verbo a elemento não-verbal que, produtivamente, implica a leitura de uma locução/perífrase verbo-nominal e da construcionalização gramatical dessa forma de predicar estados de coisas, que resultou em construção de predicação com verbo suporte, presente também em gramáticas de outras línguas.

Predicador complexo com verbo suporte é um recurso acionado com frequência e sistematicidade pelos falantes para a formação de unidades predicantes. O fenômeno de formação de predicados complexos não ocorre apenas em Português. Outras línguas disponibilizam a construção com verbo suporte, ainda que contem com mecanismos morfológicos de formação de verbos simples. Citem-se, a título de ilustração, casos de instanciação de predicadores complexos no francês (cf, para mais informações a respeito, GIRY-SCHNEIDER, 1978), no italiano (cf. QUOCHI, 2007) ou no inglês (cf. BRINTON, 2011):

“J'ai fait référence à l'écologie en citant le sommet de Kyoto en 1997 mais aussi à Durkheim qui part du principe que la sociologie devient une chance de traiter les faits sociaux comme une chose observable."' (http://plus.lefigaro.fr/ note/jai-choisi-le-sujet-scientifique-20100617-225974, acesso em 04/01/2018) "E qui non alludo alla conoscenza postuma che in età adolescenziale o in età adulta porta qualcuno dallo psicoterapeuta a cercare l'anima o direttamente in farmacia nel tentativo di sedarla; ma faccio riferimento a quell'educazione dei sentimenti, delle emozioni, degli entusiasmi, delle paure, che mette al riparo da quell'indifferenza emotiva, oggi sempre più diffusa, per effetto della quale non si ha risonanza emozionale di fronte ai fatti a cui si assiste o ai gesti che si compiono." (http://www.repubblica.it/online/cronaca/desire/ analfabeti/analfabeti.html?refresh_ce, acesso em 04/01/2018)

6 "Eu fiz referência/me referi à ecologia ao citar a Cúpula de Quioto em 1997, mas também a Durkheim, que pressupõe que a sociologia se torna uma chance de tratar fatos sociais como coisas observáveis.”

7 "E aqui não aludo ao conhecimento póstumo que na adolescência ou na idade adulta leva alguém do psicoterapeuta a buscar o estado de alma ou diretamente à farmácia na tentativa de 
"One person familiar with the matter said Brennan did not reveal sources but made reference to the fact that America's intelligence allies had provided information. ${ }^{8}$ " (https://www.theguardian.com/uk-news/2017/apr/13/britishspies-first-to-spot-trump-team-links-russia, acesso em 04/01/2018)

E os falantes não necessitam aprender todas as combinações de verbos suportes e elementos não-verbais numa língua. Assim que dominam os atributos básicos da construção com verbo suporte com base em pareamentos forma-significado mais ou menos regulares detectados mediante instanciações daquela, passam a valer-se dos atributos dessa construção para novos casos que julguem de comportamento similar, num processo de analogia: a partir de um padrão construcional de formação de predicadores complexos que envolve a operação regular de verbos suportes (relativamente previsíveis em termos lexicais) sobre elementos não-verbais (bem menos previsíveis em termos lexicais), expressões inéditas passam a ser criadas ou interpretadas.

Uma das manifestações da natureza perifrástica desse tipo de construção é a existência, em muitos casos, de verbos predicadores simples (também conhecidos como verbos plenos/principais) com significado funcionalmente equivalente ao do predicador complexo. Por exemplo:

“O governo, abre esse edital, através da MT-Par, sem fazer discussão com a categoria.” (http://www.maisfn.com.br/noticias/pedro-taques-pode-iniciar-processo-de-privatizacao-das-escolas-estaduais, acesso em 05/01/2018) [discutir ]

“O Detran-RJ vai fazer atendimento noturno para atender" a demanda por vistorias de veículos durante as paralisações dos funcionários terceirizados.” (https://g1.globo.com/rio-de-janeiro/noticia/presidente-do-detran-rj-diz-que-atendimento-sera-normalizado-em-uma-semana.ghtm, acesso em 05/01/2018)

Tais enunciados ilustram a possibilidade de substituição das perífrases por verbos predicadores simples cognatos ao elemento nominal incorporado. Entre-

sedá-lo; mas faço referência/me refiro àquela educação de sentimentos, emoções, entusiasmo e medo que protege dessa indiferença emocional, hoje cada vez mais difundida, por efeito da qual não há ressonância emocional em face dos fatos a que se assiste ou aos gestos que se copiam.”

8 "Uma pessoa familiarizada com o assunto disse Brennan não revelou fontes, mas fez referência/ se referiu ao fato de que os aliados da inteligência americana forneceram informações."

9 “CComo a PPP, o governo transfere a responsabilidade do poder público de fazer atendimento da demanda Educacional é caminho para que se inicie o processo de terceirização nas escolas públicas', aponta.” (http://www.maisfn.com.br/noticias/pedro-taques-pode-iniciar-processo-de-privatizacao-das-escolas-estaduais, acesso em 05/01/2018) 
tanto, nem sempre se encontra esse tipo de correspondência, conforme evidenciam usos (fazer ginástica, fazer esteira, dar lençol, dar carteirada, dar tilt) como os no enunciado a seguir:

“Cruzeiro ‘dá chapéu’ no Flamengo e contrata volante Rodrigo Souza (...) Os mesmos investidores que trouxeram o meia Marlone para o Cruzeiro trabalharam em prol do time estrelado, que 'deu um chapéu' na diretoria do Flamengo." (http://www.otempo.com.br/superfc/cruzeiro-d\%C3\%A1-chap $\%$ C3\%A9u-no-flamengo-e-contrata-volante-rodrigo-souza-1.764196, acesso em 5/01/2018)

O verbo suporte é um rótulo atribuído a um uso verbal que tem comportamento "léxico-gramatical": opera, na construção [Vsuporte elemento-nãoverball $]_{\text {predicador verbal complexo, }}$ como o componente com maior grau de previsibilidade de preenchimento lexical porque, em geral, corresponde a uma forma verbal recorrente na produção de várias instâncias de predicadores complexos; contribui para a formação semântica do predicador verbo-nominal, apesar de o elemento não-verbal ser o principal responsável pelas propriedades semânticas específicas do predicador que resulta dessa associação, pelo tipo de acionalidade do predicador complexo.

A natureza do verbo suporte mais previsível que a do elemento não-verbal pode ser verificada, observando-se, por um lado, uma relativa repetição na compatibilização de certas formas verbais na formação de predicadores complexos e, por outro, uma grande diversidade na compatibilização de itens não-verbais.

O verbo suporte também contribui para delimitar a natureza acional do predicador complexo: eventos (estados de coisas dinâmicos) ou situações (estados de coisas não dinâmicos).

"Nem o SBT, que transmitia o torneio caça-níquel, esperava tanta audiência para uma competição ressuscitada há pouco tempo. No Flamengo X Corinthians, o Ibope chegou a 23 pontos contra 21 pontos da Rede Globo. Em televisão, surrar a Rede Globo em horário nobre representa o mesmo que o Madureira dar um chocolate ${ }^{10}$ no Milan. Para entender o fenômeno, deve-se partir do pressuposto de que o torcedor não é bobo.” (Placar Magazine, mar. 1997)

10 É usada com sentido similar ao de ganhar uma partida de futebol com uma grande diferença de gols no placar. A compatibilização dos itens dar e levar contribui para marcar diferença na perspectivação dos participantes da cena (agente ou paciente perfilado como argumento sujeito). 
“O pós-jogo foi marcado por muita confusão. O comandante do policiamento local foi ao vestiário do Grêmio pedir explicações sobre a suposta agressão de Tcheco em Petraglia. Houve ainda pancadaria entre jogadores dos dois times, iniciada quando Claiton, do Atlético-PR, entrou no túnel gritando que o Grêmio levou um chocolate. A resposta foi uma voadora de Eduardo Costa, segundo informa a Rádio Gaúcha.” (http://globoesporte. globo.com/ESP/Noticia/Futebol/Campeonatos/0,,MUL165535-4276,00. html, acesso em 05/01/2018)

"A sombra da Lua, que encobriu o Sol, se desloca 4 mil quilômetros por hora. É muito rápida. Ela percorre quase toda a superfície da Terra em apenas três horas.

Este fenômeno aconteceu pela última vez em 1940. "Foi muito bonito. Eu tinha nove anos e aconteceu pouco antes do almoço. Foi durante a Segunda Guerra Mundial. O dia estava muito bonito e escureceu completamente. Ficou noite, e o céu ficou cheio de estrelas”, lembra Dona Mirian.” (http://g1.globo.com/ bomdiabrasil/0,,MUL814960-16020,00-ESPETACULO+NO+CEU.html, acesso em 05/01/2018)

No predicador verbo-nominal resultante da construção, o verbo suporte presta-se, especialmente, à codificação, em sentenças finitas, das categorias gramaticais de verbo (tempo, modo, aspecto, número e pessoa) e, assim, serve de suporte gramatical ao elemento não-verbal ao qual se alia conferindo-lhe função predicante.

Entre os atributos desse tipo de construção, importa, sem sombra de dúvida, a configuração morfossintática do elemento não-verbal. Esse slot pode ser preenchido por diversas formas (inclusive, por formas linguísticas oriundas de outras línguas, haja vista exemplos como fazer spinning, dar um like, dar zoom, fazer checkup, dar print), é preenchido frequentemente por um nome predicante, que, por sua vez, tem relação com formas verbais: fazer avaliação, fazer um levantamento, fazer um cálculo, fazer um atendimento, fazer investigação, fazer pesquisa. Tal valor no conjunto de possibilidades do atributo configuração morfossintática do elemento não-verbal favorece o reconhecimento da unidade complexa como unidade de predicação verbal. Soma-se a esse atributo a relativa regularidade na configuração formal e referencial com que tal elemento não-verbal se apresenta: geralmente nome "nu" ou acompanhado de artigo, não especificado ou modificado, com significação genérica e com função classificatória em termos de acionalidade.

Naturalmente, é preciso levar em consideração, conforme já salientado em Machado Vieira (2014), que a construção com verbo suporte pode licenciar diferentes padrões construcionais de predicadores complexos (microconstruções). Sintetizam-se, aqui, três destaques quanto a isso. 
$1^{\circ}$ ) Pode licenciar: desde (a) padrões construcionais envolvendo verbos que se situam numa categoria fronteiriça à de verbo predicador (uma espécie de verbo semi-suporte), uma vez que, em certa medida, têm aparência gramatical de verbo suporte (pois, operando sobre um elemento não-verbal, conferem-lhe estatuto verbal e com este formam unidades funcionais de predicação verbal com papel similar ao de um verbo pleno), porém não são tão rotineiramente empregados para a formação regular de exemplos de predicadores complexos; até (b) padrões construcionais envolvendo formas verbais produtivas em várias instâncias de uso com tal configuração, tais como são os verbos fazer, dar, ter e ficar, entre outros. Por exemplo:

A) “Abrir mão do passado leva a uma memória mais saudável." (http:// www.otempo.com.br/interessa/abrir-m\%C3\%A3o-do-passado-leva-a-uma-mem\%C3\%B3ria-mais-saud\%C3\%A1vel-1.1544479, acesso em 05/01/2018)

B) “"RECORD» DÁ UMA MÃO À FESTA DO FC PORTO.” (http:// www.record.pt/futebol/futebol-nacional/liga-nos/fc-porto/detalhe/ record-da-uma-mao-a-festa-do-fc-porto.html, acesso em 05/01/2018)

$2^{\circ}$ ) Pode, ainda, licenciar: desde (a) padrões construcionais, que são oriundos de um processo regular/sistemático de compatibilização de formas nos slots da construção gramatical de predicação com verbo suporte (como revelam exemplos já expostos, faz negociação, fazer discussão, fazer atendimento) com algum grau de composicionalidade; até (b) padrões construcionais, que, ademais, passaram por um processo de construcionalização lexical (ou lexicalização, assim como abordado por ESTEVES, 2012, e OLIVEIRA, 2013), e, então, são menos ou não composicionais. Exemplos dos casos referidos como (b) são:

B.1) "Que tal uma voltinha na moto do novo filme do Batman nos shoppings de São Paulo? (...) A exposição aberta ao público começa no dia 15, no Shopping Market Place, onde fica até o dia 17. Em seguida, a moto ficrá no JK Iguatemi, entre os dias 18 e 20, e, por fim, no Shopping Iguatemi, nos dias 21, 22 e 23 de julho. Vamos dar uma voltinha?" (http://www.jb.com.br/heloisa-tolipan/noticias/2012/07/11/quetal-uma-voltinha-na-moto-do-novo-filme-do-batman-nos-shoppings-de-sao-paulo/, acesso em 05/01/2018)

B.2) "Colunista da Folha volta a chutar o pau da barraca! (https:// www.ocafezinho.com/2014/03/03/colunista-da-folha-volta-a-chutar-o-pau-da-barraca/, acesso em 05/01/2018)

Alguns padrões construcionais são semilexicalizados, são parcialmente especificados (como se vê no primeiro exemplo anteriormente, dar uma 
voltinha, e, ainda, no exemplo já citado dá uma mão), pois envolvem um slot estrutural preenchido mediante forma verbal que pertence a um conjunto de possibilidades lexicais mais restrito e produtivo (formas verbais instrumentais, gramaticalizadas, como o de certos usos do verbo dar) e outro espaço estrutural de preenchimento lexical mais amplo em que acolhem formas com valor metafórico ou metonímico e, assim, atingem menor grau de composicionalidade.

Outros padrões construcionais são lexicalizados, totalmente especificados (como ilustra o segundo exemplo, chutar o pau da barraca), não composicionais (quando implicam, no todo, sentido metafórico ou metonímico e cristalização de forma e de conteúdo). Os padrões construcionais desse tipo que alcançam idiomaticidade lexical, morfossintática, semântico-pragmática e de frequência resultam de um processo que vem sendo chamado de construcionalização lexical, já que atingem, em geral instantaneamente, um pareamento forma-significado completamente novo e idiossincrático, que não é acessado ou previsto a partir da combinação regular das propriedades das suas partes constitutivas, nem é fonte produtiva de novos padrões construcionais/types ou construtos/ tokens. $\mathrm{O}$ acesso ao significado das expressões complexas instanciadas por tais padrões depende de conhecimento idiossincrático, guardado de forma altamente individualizada (ainda que elas sejam reiteradas, de modo fossilizado, numa comunidade linguística). Um falante não nativo do Português até reconhecerá a forma complexa como um todo verbal/predicador (por força de atuação semi-suporte do componente verbal), mas não o sentido dela (estritamente com base nela ${ }^{11}$ ).

Já os padrões construcionais com verbo suporte não lexicalizados (não idiossincráticos) - que advêm de regularidade morfossintática e semântico-pragmática, ainda que propiciem espaço para certa irregularidade lexical (especialmente por conta da alta imprevisibilidade lexical do preenchimento de sua parte não-verbal), assim como grande frequência de ocorrência e de tipo - vinculam-se a padrões construcionais gramaticais com algum grau de composicionalidade e produtivos no licenciamento de expressões complexas, mais precisamente de predicadores verbais complexos. O acesso a essas formas baseia-se no pareamento geral \{[Vsuporte + elemento não-verbal (sem função referencial, mas com função

11 Até poderá desconfiar da acionalidade da forma complexa por força do contexto discursivo em que se materializa, mas não exatamente por conta de traços de significação dela. 
classificatória do estado de coisas) $]_{\text {Verbo predicador (complexo) }}$ Participante $\left.\}_{\mathrm{n}}\right\}_{\text {Predicação, }}$ em que o Participante é maior ou igual a zero.

$\left.3^{\circ}\right)$ Pode licenciar padrões construcionais que envolvem a compatibilização de formas verbais e elementos não-verbais um pouco mais especificados que, nem por isso, se envolvem necessariamente num processo de construcionalização lexical, mas ainda advêm, em geral, da construção gramatical de predicação com verbo suporte. Só que, nas instanciações licenciadas por tais padrões, está em jogo uma funcionalidade diferente da de "predicar": uma marcação de nuance aspectual (pouca ou não duratividade) ou uma marcação de atitude (inter)subjetiva frente ao estado de coisas conceptualizado (modalidade ${ }^{12}$ ). Neste caso, considera-se, em linhas gerais, que o conceptualizador pode conceber um estado de coisas com objetividade ou (inter)subjetividade: ou se apreendem os estados de coisas como se configuram "na realidade objetiva" ou se apreendem os estados de coisas com base na perspectivação de certos aspectos destes que pode representar apenas a atitude ou a avaliação subjetiva do enunciador ou, ainda, uma atenção ou preocupação deste com outro (o interlocutor, frequentemente).

É cada vez mais produtiva a instanciação, nesse tipo de mesoconstrução, dos verbos ter, fazer e especialmente dar acompanhados de elementos não-verbais com sufixo de grau diminutivo, como pesquisas em desenvolvimento no Projeto PREDICAR vêm revelando (TRAVASSOS, 2016).

“Jornalista passará primeiro Dia das Mães com os filhos adotivos, que ganharam novo lar há três meses. (...) E sinceramente, a sensação que tenho é que eles sempre pertenceram à família, mas deram uma saidinha e voltaram. E são apenas pouco mais de três meses de convivência." (http://revistaglamour.globo.com/Na-Real/noticia/2015/05/jornalista-passara-primeiro-dia-das-maes-com-os-filhos-adotivos-que-ganharam-novo-lar-ha-tres-meses.html, acesso em 05/01/2018)

"A criança ligou para o serviço de emergência 911 às $20 \mathrm{~h}$ e denunciou a mãe, que exigia que ele fosse dormir. Um policial foi até a casa da família e teve uma conversinha com o menino queixoso. Ninguém foi indiciado, de acordo com o jornal "The Enterprise"." (http://blogs.oglobo.globo.com/pagenotfound/post/menino-revoltado-com-ordem-de-ir-para-cama-chama-policia-487517.html, acesso em 05/01/2018)

12 De acordo com Raposo (2013), modalidade é a expressão, por meio de mecanismos linguísticos, de atitudes e opiniões dos enunciadores e das entidades referidas por estes em relação ao conteúdo da proposição. 
"As pessoas precisam entender que não basta chegar aqui e fazer uma reuniãozinha de empresários em um hotel à beira do rio.” (http://politica.estadao.com.br/noticias/geral,psdb-nao-pode-viver-de-encantamento-diz-arthur-virgilio,70002026482, acesso em 05/01/2018)

Todas essas possibilidades de instanciação da construção de predicação com verbo suporte (em alguns casos, com semi-suporte), licenciadas gramaticalmente e, ainda, em alguns casos submetidas a construcionalização lexical, compatibilizam-se, à semelhança de predicadores simples, em construções gramaticais de estrutura argumental (pessoais ou impessoais; intransitivas ou transitivas), propiciando, assim, alternativa gramatical à função cognitiva de conceptualização de estados de coisas.

A configuração da estrutura da oração resultará, então, da fusão entre os papéis participantes do predicador verbal (simples ou complexo) e os papéis argumentais da construção de predicação de estrutura oracional (mais gerais e previsíveis na gramática da língua), com base no Princípio da Coerência Semântica ("Semantic Coherence Principle", de acordo com o qual, em linhas gerais, "o papel participante do verbo e o papel argumental da construção devem ser semanticamente compatíveis”, GOLDBERG (2006, p. 40)) e o Princípio da Correspondência ("Correspondence Principle", segundo qual "os papéis participantes perfilados do verbo ${ }^{13}$ devem ser codificados mediante os papéis argumentais perfilados da construção" de estrutura argumental, idem). Além dos papéis participantes fornecidos pelos predicadores complexos, outros papéis previstos apenas pela construção de predicação podem materializar-se na sentença como uma contribuição desta. Ilustra isso exemplo como:

"Sonia Abrão, 56 anos, adora falar, conversar. Comunicação é com ela mesma. Tanto é que na adolescência, deu uma "rebolada" em seu pai quando se matriculou escondida no curso de jornalismo na Faculdade de Comunicação SocialCasper Líbero, em SãoPaulo.” (http://www.r7.com/r7/media/2017/2017-paporeto/soniaabrao/index.php, acesso em 05/01/2018)

Nele, percebe-se a presença de um argumento entidade afetada por operação de um participante controlador, que não é perfilado por papel participante do predicador verbal "dar uma rebolada", mas uma contribuição da construção transitiva.$^{14} \mathrm{O}$ papel participante perfilado pelo predicador verbal "dar uma rebolada" é o de participante entidade que controla uma ação.

13 Aqui também predicador verbal complexo.

14 Outro exemplo de contribuição da construção de estrutura argumental pode ser visto na sentença:

"Com uma piscadinha, ela se virou de costas para eles e deu uma rebolada para seu admirador.". 


\section{A REDE DE PADRÕES CONSTRUCIONAIS LICENCIADOS PELA CONSTRUÇÃO DE PREDICAÇÃO COM VERBO SUPORTE}

O mapeamento das relações entre padrões constucionais licenciados a partir da construção de predicação com verbo suporte, a mais esquemática e, por conseguinte, a que apresenta mais possibilidades de compatibilização de formas lexicais diferentes, exige a confluência de olhares teórico-metodológicos ${ }^{15}$ distintos: às vezes, com inclinação sociofuncionlista ou socioconstrucionista, já que se enfocam formas de predicar que correspondem a atributos/condições funcionais relativamente similares; e, muitas vezes, com perspectiva apenas funcional-construcionista, porque governada pelo intuito de se detectarem os valores dos atributos envolvidos nos pareamentos forma-função que a construção como um todo implica ${ }^{16}$.

Machado Vieira (2016) mostra como essa confluência tem o potencial de ser explorada, aproveitando-se o know-how alcançado na Teoria Sociolinguística no que diz respeito ao estudo da variação. Com base em Hilpert (2014) e Cappelle (2009), defende que é viável supor, a depender das condições funcionais, dos contextos ou dos domínios discursivos de uso observados, relação de similaridade (por analogia) entre certas instanciações de predicadores complexos com verbo suporte e predicadores simples (dar início e iniciar; dar uma piscada e piscar, dar uma curtida e curtir, fazer uma pergunta e perguntar; ir à loucura ${ }^{17}$ e enlouquecer) ou entre certas instanciações de predicadores complexos (como dar uma piscada, dar uma piscadela e dar uma piscadinha, dar uma fugida, dar uma fugidela, dar uma fugidinha; fazer queixa e dar queixa; fazer xerox e tirar xerox; ir à loucura e ficar louco). E, para lidar com essa concepção, chega a cogitar da possibilidade proposta por Cappelle de se considerar o construto teórico "allostruction" (cunhado por analogia a "alofone" e "alomorfe"). E, assim, tais instancia-

15 Afinal, "A gramática sempre proporciona aos falantes, formas alternativas de codificar uma certa parte da substância conceptual. Além disso, os falantes raramente são inteiramente livres para fazer uma escolha entre as alternativas, já que cada opção gramatical está usualmente sujeita a uma série de restrições, algumas das quais podem muito sutilmente guiar os falantes a fazer as escolhas que eles fazem.” (CAPPELLE, 2009, p. 1)

16 É o caso, por exemplo, da pesquisa de Doutoramento de Valente (2018), entre outras pesquisas do Projeto PREDICAR.

17 Exemplo da tese de Oliveira (2013): "Daniel Rocha vai a evento de moda e fãs vão à loucura. Daniel Rocha foi a um shopping em Brusque, Santa Catarina, nesta segunda-feira, 6, e causou o maior tumulto. Uma multidão de fãs aguardava o ator, que interpreta o Roni na novela "Avenida Brasil", e foi à loucura quando ele apareceu." (www.cenariomt.com.br - acesso em 07 de agosto de 2012) 
ções serviriam para sugerir a possibilidade de certos padrões construcionais (de certas microconstruções) serem, nessa rede, aloconstruções.

O esquema construcional de predicação verbal pode ter seu slot de predicador verbal preenchido por predicadores simples (itens lexicais verbais) ou por predicadores complexos oriundos da macroconstrução de predicação com verbo suporte. Esta, por sua vez, licencia, por um lado, predicadores complexos com formas verbais quase predicadoras, semi-suportes (do tipo abrir, em abrir mão ou abrir fogo, deitar, em deitar o cabelo; pendurar, em pendurar as chuteiras; perder, em perder a cabeça; descer, em descer a lenha), que geralmente se envolvem em predicadores complexos os quais, por sua vez, se submetem à condição de não composicionalidade mais acentuada e de cristalização morfossintática e semânti$\mathrm{ca}$, num processo de construcionalização lexical. E, por outro lado, licencia predicadores complexos com verbos suportes (do tipo fazer, dar, ter, haver, ficar, tomar, levar, pegar, deixar, entre outros itens do Português mais produtivamente acionados como instrumentos de verbalização nesse slot), sistematicamente formados segundo certas regularidades configuracionais descritas na seção anterior. Ocorre que especialmente esse segundo caso de mesoconstrução com verbo suporte pode ter, mais frequentemente, o slot de elemento não-verbal preenchido por elementos de natureza diversa: por nomes predicantes (e, então, com verbalidade e estrutura de participantes inerente) ou não; por formas advindas de outras línguas; por nomes com sufixos de grau; por nomes com modificadores (e, por conseguinte, já com algum caráter de referencialidade, diferentemente da configuração prototípica de predicador complexo com verbo suporte, e, então, com menor grau de coesão); por nomes com valor metafórico ou metonímico (fazer a cabeça; dar uma mão; fazer questão, no sentido de querer; dar/levar um chocolate). Essa diversidade de possibilidades de preenchimento gerará muitas microconstruções individuais entre as quais poderá emergir (ou não) algum grau de similaridade, por um processo analógico, dependendo dos valores de seus atributos funcionais, bem como de condições do domínio discursivo em que convencionalmente se concretizem ou sejam percebidas/compreendidas.

\section{POSSIBILIDADES DE SIGNIFICADO FUNCIONAL DE USOS DE PREDICADORES COMPLEXOS NA CONCEPTUALIZAÇÃO DE ESTADOS DE COISAS}

Tendo em vista o princípio da expressividade maximizada (GOLDBERG, 1995), consoante o qual o inventário de padrões construcionais numa gramática é maximizado por propósitos comunicativos, formas diferentes de predicar estados de coisas relacionam-se a certa(o)s condições/atributos funcionais (semânticos, discursivos, pragmáticos e sociais). Assim sendo, é imperativo, quando se lida com 
a temática, investigar as condições sob as quais os falantes recorrem a uma ou outra das duas construções de predicação: predicadores simples e complexos.

Entre as possibilidades de significado semântico, discursivo, pragmático e social associadas à construção de predicação mediante predicadores complexos, conforme já descrito em Machado Vieira (2001), estão estas: (i) propiciar a codificação de um efeito semântico singular, que não é obtido por meio do recurso a uma forma verbal simples, mesmo que (quase) correspondente, cognata ou não ao elemento não-verbal (dar uma carteirada; dar entrada e entrar; dar parabéns, parabenizar; ter uma conversinha, conversar; fazer ginástica, exercitar-se; ir às urnas, votar); (ii) simplesmente diversificar os mecanismos linguísticos explorados na construção textual ${ }^{18}$; (iii) prescindir de complementação por tencionar-se evitar a explicitação de participante envolvido na predicação ("Amanhã farei sugestões durante a reunião.”); (iv) não usar clítico (fazer referência, referir-se; ficar encantado, encantar-se), cuja supressão no Português se revela uma tendência, segundo já menciona Kato (1996, p. 233) e detecta Alves (2011), esta em pesquisa empírica sobre a alternância entre predicadores complexos e predicadores simples pronominais.

A tais possibilidades, somam-se, ainda, pelo menos duas outras condições, recentemente observadas, por meio de exame de dados do uso e de pesquisa de percepções e avaliações subjetivas sobre alguns desses dados, em estudos mais recentes do Projeto PREDICAR.

Segundo Brown; Levinson (1987), qualquer ato de fala representa, em alguma medida, ameaça às faces, imagens (bens simbólicos), dos interlocutores. No intuito de atenuar tal fato, implementam-se estratégias de polidez. Entre tais estratégias, reconhece-se, no uso do Português, o emprego de certos predicadores complexos com tal propósito.

É, por exemplo, cada vez mais frequente, na escrita acadêmica (como observam SARAIVA, 2013, MOURA, 2017, e MACHADO VIEIRA, 2017), o recurso a predicador complexo em que se compatibilizam os verbos suportes ter-se e haver. De acordo com Machado Vieira (2017), trata-se de uma forma de promover a impessoalização discursiva (esperada no domínio discursivo acadêmico) e, desse modo, conseguir mitigar uma eventual ameaça à face do locutor ou interlocutor na

18 Por exemplo: “A cereja no bolo é a demonização que é feita no seguinte parágrafo: "Quando se fala em livre conhecimento, entre outras coisas se quer dizer que se é contra criminalizar alguém por baixar música da internet ou por fazer uma cópia de um livro na faculdade.” (...) É óbvio que ninguém vai sair por aí prendendo quem baixou MP3 da web ou copiou um livro no xerox da faculdade. Esses são sintomas de uma sociedade subdesenvolvida como a nossa." (https://jornalggn.com.br/blog/luisnassif/a-questao-dos-direitos-autorais, acesso em 05/01/2018) 
interação sociocomunicativa mediante a imposição de uma certa distância do conteúdo da predicação explorado na proposição em relação àquele. Assim sendo, cada vez mais se encontram, nos textos acadêmicos, instâncias de uso de predicadores complexos com verbo suporte como as destacadas nos enunciados a seguir:
"Segundo a coordenadora pedagógica Lucimara Karpe Canova, durante a reunião teve-se conhecimento da real importância da formação do Conse- lho para oferecer melhor qualidade de vida para as pessoas com deficiência. 'Reuniremos todos os segmentos para pensar em políticas públicas que ga- rantam o direito e promovam melhorias na vida das pessoas com deficiência', salientou ela."
"Particularmente, independentemente do pouco ou muito tempo que vão du- rar, todo projeto ou ideia serão importantes desde que atinjam sua missão ou objetivos. Porém, quando estes são pensados para que aconteçam para além da própria existência dos que os desejaram, e que avancem no tempo, tem-se necessidade de buscar algo mais do que a pronta e contínua motivação dos seus idealizadores." (http://www.jb.com.br/sociedade-aberta/noticias/2014/ 08/12/um-projeto-para-nosso-tempo/, acesso em 05/01/2018)
"Houve discordância de que houvesse necessidade já que a matéria havia sido apreciada na CCJ e votada em primeira votação em plenário sendo de amplo conhecimento de todos os parlamentares. Também houve acusação de que o pedido de vista era uma manobra a pedido do Paço, para protelar o trâmite e atrasar a aprovação do projeto. Por outro lado, alguns vereado- res da comissão alegavam que era direito do vereador pedir vista. Os âni- mos se exaltaram e houve troca de acusações. (...)" (http://www.goiania. go.leg.br/sala-de-imprensa/noticias/clecio-alves-pede-abertura-de-proces- so-disciplinar-contra-oseias-varao, acesso em 05/01/2018)

As duas microconstruções (com ter-se e haver) licenciadas por meio da construção de predicação com verbo suporte mitigam as marcas da pessoa discursiva e/ ou da força indutora (participante) do estado de coisas na verbalização deste. É lógico que elas o fazem diferentemente: a microconstrução com haver propicia, geralmente, o apagamento do enunciador e/ou da força indutora do estado de coisas ${ }^{19}$

19 Outro exemplo: "Neste domingo (30), Eduardo Bandeira de Mello, presidente do Flamengo, admitiu que a arbitragem errou a favor do Flamengo durante o empate por $1 \mathrm{a} 1 \mathrm{com}$ o Corinthians, na Arena Corinthians, em jogo válido pela $17^{\mathrm{a}}$ rodada do Campeonato Brasileiro. $\mathrm{O}$ time paulista teve gol legal anulado por impedimento quando a partida ainda estava 0 a $0(\ldots)$ Em relação à polêmica da partida contra o Santos, quando árbitro marcou pênalti para a equipe do litoral paulista e voltou atrás, Bandeira afirmou que não houve erro." (https://esporte.uol. com.br/futebol/ultimas-noticias/2017/07/30/presidente-do-flamengo-admite-que-arbitragem- 
(frequentemente, em eventos com participante agente, causa/força ou experienciador, ou em situações/estados de coisas não dinâmicos, com participante experienciador), ao passo que a microconstrução com ter-se opacifica sua existência, podendo, também, colaborar para que o resultado final da predicação assuma contorno de evento ou estado com referência genérica (que se ligue a nenhum participante específico no mundo biossocial). Tais microconstruções, respectivamente, ensejam mais acentuadamente ou menos que a conceptualização do estado de coisas assuma contorno de evento ou estado natural/espontâneo (que se realiza ou apresenta, em alguma medida, por si só).

Predicadores complexos com verbo suporte haver vêm ganhando terreno. Não é raro encontrar instanciações até do predicador complexo "haver (a) existência", inclusive em texto acadêmico, como a que se registra neste exemplo retirado de texto jornalístico:

"O relator do processo, ministro Edson Fachin, votou para receber integralmente a acusação, afirmando que há a existência de indícios mínimos para se afirmar que houve o crime de peculato." (https://g1.globo.com/politica/ noticia/stf-rejeita-denuncia-contra-deputado-ariosto-holanda-por-peculato.ghtml, acesso em 04/01/2018).

É também cada vez mais produtiva (em termos de produtividade token/ocorrência e produtividade type/padrão construcional) a compatibilização em predicador complexo com verbo suporte de elementos não-verbais com afixos de grau, como, por exemplo, em:

"Apesar das alternâncias de posse de bola e do jogo truncado no início, Cruzeiro e Ceará acabaram por fazer um jogaço em Osasco. Aproveitando dois lances capitais na partida, a Raposa marcou 2 a 0 , quando o Vovô estava pressionando.” (http://globoesporte.globo.com/ce/jogo/16-01-2016/ cruzeiro-ceara/, acesso em 05/01/2018)

TRAVASSOS (2016) enumera, com base em pesquisa de dados em textos do domínio jornalístico produzidos desde o início do século XX, diversas microconstruções com elementos não-verbais contendo sufixo de grau diminutivo, tais como estes: a) (uma) X-ad(a/inha)/-id(a/inha) (modificador); b) (uma) X-adela(-zinha) (modificador); c) (uma) X-(z)inha (modificador). Por exemplo: a) dar risa-

-ajudou-contra-o-corinthians.htm, acesso em 05/01/2018)

Há, entretanto, enunciados em que a força indutora (fonte de energia) passa à condição de oblíquo, preservando-se na predicação, ainda que sem a condição de proeminência de sujeito: Admitiu que houve erro da arbitragem a favor do Flamengo. 
da, dar uma risadinha, dar uma lida, dar uma emagrecidinha; b) dar uma espiadela, dar uma escorregadela; c) dar uma voltinha, fazer uma farrinha, ter uma conversinha.

"Passar muitas horas no trânsito, sem poder dar uma fugidinha para fazer xixi quando a necessidade aperta: esta é a realidade de vários motoristas de ônibus de Seattle, nos Estados Unidos. Para tentar contornar o problema, os profissionais chegam a usar fraldas geriátricas e carregar garrafas nos ônibus para urinar." (https://extra.globo.com/noticias/mundo/motoristas-de-onibus-sao-obrigados-usar-fraldas-em-seattle-nos-estados-unidos14653168.html, acesso em 05/01/2018)

"Hoje em dia, dar uma olhadela no WhatsApp, curtir fotos no Instagram e falar no chat do Facebook se tornaram práticas mais comuns dentro das quatro paredes de um quarto de motel do que necessariamente algum tipo de movimentação caliente." (https://oglobo.globo.com/rio/muito-alem-dosexo-14626672, acesso em 05/01/2018)

Segundo a pesquisadora, instanciações de predicadores complexos com tais possibilidades de preenchimento do slot elemento não-verbal geralmente se atualizam, no discurso, ora mais associadas a um valor aspectual (não durativo ou pouco durativo) do estado de coisas ora mais vinculadas a uma atitude do enunciador de perspectivação subjetiva ou intersubjetiva do estado de coisas:

"No texto original, Giovanna diz que chegou à boate às $2 \mathrm{~h} e$, diante de uma fila enorme, foi conversar com a hostess. "Comentei que tinha um blog e que fazia trabalhos em parceria com a Capricho e perguntei se poderia dar uma olhada na festa antes de todo mundo pagar para entrar - afinal, não é todo dia que a gente pode pagar 80 reais para entrar em uma balada [homens pagavam 120, estávamos em cinco homens e uma mulher", relatou." (https://noticias.bol.uol.com.br/ultimas-noticias/tecnologia/2013/07/31/ dei-risada-de-mim-mesma-afirma-blogueira-da-capricho-apos-virar-meme-na-internet.htm, acesso em 05/01/2018)

"Questionado a respeito da postura de Felipe Melo no dia a dia do Palmeiras, Mattos saiu em defesa do volante e até pediu atenção de Tite, técnico da Seleção, ao futebol do jogador.

- Felipe é muito do bem. Tem um papel de liderança muito forte. Não temos que recrimina-lo. Dentro de campo, está muito bem. O Tite até poderia dar uma olhadinha nele. Não deve nada na sua posição. É um cara espetacular, obediente e superprofissional. O Felipe é autentico. No dia em que (ele) parar vamos sentir falta." (https://globoesporte.globo.com/futebol/times/palmeiras/noticia/mattos-cita-intimidade-no-elenco-para-dar-esporro-e-ve-guedes-protegido-no-palmeiras.ghtml, acesso em 05/01/2018) 
No primeiro exemplo anteriormente citado, o que sobressai é a momentaneidade ou brevidade do tempo interno do estado de coisas, ou a superficialidade deste. No segundo exemplo anteriormente citado, o que está em cena, de fato, é o encaminhamento crítico ao técnico de futebol Tite de que bastaria a este "olhar com cuidado"/“vigiar" Felipe Melo, mas o que se apresenta é uma atitude de mitigar o estado de coisas e, a um só tempo, fazer a sugestão com polidez, uma vez que, em alguma medida, esta não se encaixa tão confortavelmente no que se concebe socialmente como desejável no contexto de negociação de sentido entre os participantes de uma interação ou como atribuição esperada de um participante (ou do interlocutor ${ }^{20}$ ).

Detecta-se, em certas instanciações de predicadores complexos desse tipo, um processo de codificação morfossintática da perspectivação de aspectos do estado de coisas e condições pragmáticas, (inter)subjetividade. Trata-se de uma estratégia discursiva de formular uma predicação com base num enfoque de conceptualização do estado de coisas por parte do enunciador, levando este em conta sua ótica de observação e compreensão do estado de coisas em si, do interlocutor e demais elementos do contexto de interação e da predicação.

Por fim, salienta-se, ainda quanto ao significado funcional, a imagem social entre brasileiros a que se sujeitam os predicadores complexos com verbo suporte. Esteves (2008) e Machado Vieira; Esteves (2009), ao lidarem com o tema enfrentando o problema da avaliação subjetiva mediante metodologia de pesquisa de atitudes linguísticas, detectaram que, socialmente, instanciações de predicadores complexos com verbo suporte tendem a ser associadas, pelos falantes, a situações de comunicação oral, em que prevalece certa informalidade, em que se supõe algum grau de intimidade entre os interlocutores e, por vezes, uma atitude de gentileza ou matizes de ironia e humor ou até menor letramento. Normalmente, não são tão esperadas em contextos de norma culta padrão. É interessante observar que frequentemente, quando chamam a atenção para esse aspecto discursivo quanto à expectativa de norma linguística, os falantes ou têm em mente predicadores complexos com algum grau de lexicalização ou têm em mente o fato de muitas instanciações se valerem de formas verbais que acabam por se repetir nesse tipo de construção ainda que em instanciações de predicadores diferentes. Demonstram, ao que parece, certo comedimento com relação ao emprego de ex-

20 Como se detecta em certos pedidos, como: "Nos EUA, existe um programa comunitário chamado "neighbours watching" que, em tupiniquim, significa algo como "VIZINHO OLHANDO POR VIZINHO”. No nosso passado remoto, significava o mesmo que "eu estarei fora, você poderia dar uma olhadinha na minha casa?" (http://www.sap. com.br/seguranca, acesso em 05/01/2018) 
pressões conotativas e à repetição linguística em contextos de norma culta padrão, principalmente ao registrarem suas percepções a partir da leitura de trechos de textos com expressões com verbo suporte ligados a certas fontes do domínio jornalístico ou acadêmico avaliadas, pelos falantes, como atentas à modalidade escrita padrão e a uma linguagem formal.

E o fato é que, embora a imagem social que se partilhe de predicadores complexos com verbo suporte muitas vezes ainda os relacione a contextos de oralidade, informalidade, de menor letramento e/ou de descontração, instanciações licenciadas pela construção de predicação com verbo suporte ocorrem nos mais variados domínios discursivos, gêneros textuais e fontes (escritas ou orais), conforme indicam pesquisas do Projeto PREDICAR, que há algum tempo já se voltam para usos nos domínios acadêmicos (por exemplo, SARAIVA, 2013, e MOURA, 2017) e jornalísticos (ALOIZA, 2009, e SILVA, 2009).

\section{CONSIDERAÇÃO FINAL}

A construção de predicação com verbo suporte pressupõe: (i) algum grau de gramaticalização do item verbal que com ela se compatibiliza, (ii) a integração de um elemento verbal (semi)gramaticalizado e outro não-verbal sob alguns atributos configuracionais semânticos e morfossintáticos, independentemente do tipo de verbo (semi)suporte e do elemento não-verbal que se verbaliza por conta daquele e, então, (iii) a gramaticalidade da construção em si, que tem emprego similar ao de um verbo pleno na estruturação de uma predicação verbal de argumentos, tendo a possibilidade de determinar papéis participantes, se não representar uma cena impessoal (como fez sol ou ficou noite).

Os falantes recorrem à construção com verbo suporte para, entre outras finalidades, construir sentidos que não são conceptualizados por meio de outras formações linguísticas, produzir e compreender novas instanciações de predicadores complexos, exprimir atitudes numa interação social.

\section{REFERÊNCIAS BIBLIOGRÁFICAS}

ALOIZA, Adriana Guimarães. As construções resultativas com deixar em textos jornalísticos brasileiros. Dissertação (Mestrado em Letras Vernáculas) - Faculdade de Letras, Universidade Federal do Rio de Janeiro, Rio de Janeiro, 2009.

ALVES, Olívia Maia de Mello. Estudo sociofuncionalista da alternância entre predicadores pronominais simples e predicadores complexos. Dissertação (Mestrado em Letras Vernáculas) - Faculdade de Letras, Universidade Federal do Rio de Janeiro, Rio de Janeiro, 2011. 
BRINTON, Laurel J. The grammaticalization of complex predicates. In: NARROG, Heiko; HEINE, Bernd (eds.). The Oxford Handbook of Grammaticalization. New York: Oxford University Press, 2011, p. 559-569.

BROWN, Penelope; LEVINSON, Stephen C. Politeness: some universals in language usage. Cambridge: Cambridge University Press, 1987.

CAPPELLE, Bert. Can we factor out free choice? In: DUFTER, Andreas; FLEISCHER, Jürg; SEILER, Guido. Describing and Modeling Variation in Grammar. Berlin/New York: Mouton de Gruyter, 2009, p. 183-199.

DIK, Simon C. Theory of functional grammar. Part 1. The structure of the clause. Kees Hengveld (ed.). Berlin: Mouton de Gruyter, 1997.

ESTEVES, Giselle Aparecida Toledo. Construções com DAR + sintagma nominal: agramaticalização desse verbo e a alternância entre perífrases verbo-nominais e predicadoressimples. Dissertação (Mestrado em Letras Vernáculas) - Faculdade de Letras, Universidade Federal do Rio de Janeiro, Rio de Janeiro, 2008.

A lexicalização de expressões DAR/FAZER + SN: fiz sacrifício, dei conta. Tese (Doutorado em Letras Vernáculas) - Faculdade de Letras, Universidade Federal do Rio de Janeiro, Rio de Janeiro, 2012.

GIRY-SCHNEIDER, Jacqueline. Les nominalisations en français: l'opérateur "faire" dans le lexique. Genéve: Librairie Droz. Langue \& Cultures, 9, p. 5-54, 1978.

GOLDBERG, Adele. Construction. A construction grammar approach to argument structure. Chicago: The University of Chicago Press, 1995.

. Constructions at work: the nature of generalization in language. Oxford: OxfordUniversity Press, 2006.

HILPERT, Martin. Construction grammar and its aplication to English. Edinburgh: Edinburgh University Press, 2014.

MACHADO VIEIRA, Marcia dos Santos. Sintaxe e semântica de predicações com verbofazer. Tese (Doutorado em Letras Vernáculas) - Faculdade de Letras, Universidade Federal do Rio de Janeiro, Rio de Janeiro, 2001.

. Perífrases verbais. Estudos linguísticos/Linguistic studies, 5. Edições Colibri, CLUNL, Lisboa, 2010, p. 409-429.

Idiomaticidade em construções com verbo suporte do Português. SOLETRAS

- Revista do Departamento de Letras da FFP/UERJ, n. 28, p. 99-125, jul.-dez. 2014.

Variação e mudança na descrição construcional: complexos verbo-nominais. Revista LinguíStica, [S.l.], p. 152-170, dez. 2016.

Expressões impessoais no discurso acadêmico brasileiro. Letrônica - Revista Digital do Programa de Pós-Graduação em Letras da PUCRS, v. 10, n. 1, p. 82-95, jan.-jun. 2017.

MACHADO VIEIRA, Marcia dos Santos; ESTEVES, Giselle Aparecida Toledo. Metodologia de avaliação subjetiva de usos linguísticos em variação. In: LOPES, Celia; REICH, 
Uli. Romania. Variação linguística em megalópoles latino-americanas, 39, p. 237-266, 2009.

MOURA, Bismarck de Zanco. Construções verbo-nominais no Português: haver + nome predicante. Dissertação (Mestrado em Letras Vernáculas) - Faculdade de Letras, Universidade Federal do Rio de Janeiro, Rio de Janeiro, 2017.

OLIVEIRA, Vinícius Maciel. Construções de movimento no Português Brasileiro. Tese (Doutorado em Letras Vernáculas) - Faculdade de Letras, Universidade Federal do Rio de Janeiro, Rio de Janeiro, 2013.

QUOCHI, Valeria. A usage-based approach to light verb constructions in italian:development and use. Tesi di Dottorato - Università de Pisa, 2007. RAPOSO, Eduardo Buzaglo Paiva et al. (orgs.). Gramática do Português. V. I e II. Lisboa: Fundação Calouste Gulbenkian, 2013.

SARAIVA, Eneile Santos. A construção TEM-SE no Português Brasileiro escrito: uma análise sociofuncionalista. Dissertação (Mestrado em Letras Vernáculas) - Faculdade de Letras, Universidade Federal do Rio de Janeiro, Rio de Janeiro, 2013.

SILVA, Leila Vasti da Paz. Predicações com o verbo levar: aspectos relativos à multifuncionalidade e gramaticalização. Dissertação (Mestrado em Letras Vernáculas) - Faculdade de Letras, Universidade Federal do Rio de Janeiro, Rio de Janeiro, 2009.

TRAVASSOS, Pâmela Fagundes. Construções com verbo-suporte DAR: indicação de aspecto elou outro valor? Monografia de fim de curso de Graduação - Faculdade de Letras, Universidade Federal do Rio de Janeiro, 2016. 100 fl. mimeo.

TRAUGOTT, Elizabeth Closs; TROUSDALE, Graeme. Constructionalization and construction changes. Great Britain: Oxford University Press, 2013.

VALENTE, Ana Carolina Mrad de Moura Valente. "Dar um balão" e "fazer um golaço": análise de construções $V+S N$ características da linguagem do futebol. Tese (Doutorado em Letras Vernáculas) - Faculdade de Letras, Universidade Federal do Rio de Janeiro, Rio de Janeiro, 2018. 